\title{
STRESS PROCESSES: AN ESSENTIAL INGREDIENT IN THE ENTREPRENEURIAL PROCESS
}

\author{
Andreas Rauch (University of Sydney, Australia) \\ Matthias Fink (Johannes Kepler University Linz, Austria) \\ Isabella Hatak (University of St Gallen, Switzerland)
}

\begin{abstract}
The entrepreneurial process is associated with high uncertainty. Uncertainty is also a major source of stress. Therefore, a core aim of entrepreneurs is to reduce uncertainty to an extent that allows the entrepreneurial process to unfold. However, entrepreneurship scholars have insufficiently addressed stress processes that may be associated with this uncertainty. We argue that uncertainty is the concept connecting both the entrepreneurial and stress processes. We discuss the link between the two processes regarding: (1) opportunity recognition, (2) opportunity exploitation, and (3) associated outcomes. We then illustrate how future research should incorporate the interaction between the two processes using a morphological box and discuss how such research would change the way we specify entrepreneurial process models and study entrepreneurial behavior.
\end{abstract}

Keywords: entrepreneurial process, uncertainty, stress processes, burnout

\section{INTRODUCTION}

Although abundant literature examining stress in organizational behavior exists, this literature does not appear to be applicable to the entrepreneurship context. Thus, to gain a better understanding of stress processes, researchers need to adapt these findings and focus on the processes inherent in entrepreneurship. Stress is a substantial imbalance between 
environmental demands and the response capability of the focal organism (McGrath, 1970, p. 17). Stress involves stressors, cognitive appraisal, stress responses, and behavioral results (McGrath, 1970). We argue that stress processes are important underlying factors of the entrepreneurial process. The entrepreneurial process comprises the recognition and exploitation of opportunities and associated outcomes (Shane \& Venkataraman, 2000). In fact, stress processes seem inevitable for entrepreneurs given that they invest energy in actions involving high uncertainty, long working hours, extreme time pressure, role conflicts, and ambiguity (Patzelt \& Shepherd, 2011; Wincent \& Örtqvist, 2011). Therefore, there are many reasons to assume that entrepreneurs face stress. However, many entrepreneurs are able to successfully reduce the stress associated with entrepreneurial activity (Baron, Franklin, \& Hmieleski, 2016; Stephan \& Uhlander, 2010). Nevertheless, some studies report that entrepreneurs have high stress reactions (e.g., Prottas \& Thompson, 2006; Schjoedt, 2012). Moreover, several stress theories used in entrepreneurship research suggest differing proposals for the relationship between stressors, stress reactions, and the outcomes achieved by entrepreneurs. Theories highlighting the negative effects of stress often note the role of high demands and the perception of environmental stimuli or events (Jackson \& Schuler, 1985), while other theories underline the positive effects of control and adaptive reactions to stress perceptions (Edwards, 1992; Fay \& Sonnentag, 2002).

This situation-competing theoretical assumptions and inconclusive empirical findings - prompted us to scrutinize the linkages between stress processes and the entrepreneurial process. We argue that not including stress as a major factor in theories of the entrepreneurial process could lead to spurious relationships because the theories might be imprecise. For example, opportunity recognition has been associated with knowledge and motivation (McMullen \& Shepherd, 2006). However, high stress hinders information processing and reduces motivation. Omitting stress as a factor affecting opportunity 
recognition leads to models that are misspecified. Moreover, stress processes in entrepreneurship seem to differ from stress processes in other domains. Linking stress processes with entrepreneurial processes might provide explanations for this phenomenon. Finally, linking stress processes with entrepreneurial processes allows us to theorize reciprocal relationships between these processes. Thus, our model assumes that entrepreneurial processes might affect stress processes, and stress might affect entrepreneurial processes.

We argue that uncertainty is the concept connecting the stress processes with the entire entrepreneurial process. The entrepreneurial process implies high uncertainty ex ante (Kirzner, 1997; Knight, 1921; McMullen \& Shepherd, 2006). Uncertainty, however, is also a central cause of stress at the level of the individual (Peters, McEwen, \& Friston, 2017) and can result in severe negative consequences for the entrepreneur. Thus, reducing uncertainty is essential for both the entrepreneurial process and the stress process. By linking stress processes with the entrepreneurial process via uncertainty, we postulate that entrepreneurship research should expressly account for stress processes in both theory and empirical research. We account for these linkages by examining how uncertainty and stress affect opportunity recognition, opportunity exploitation, and associated outcomes in a reciprocal way. In addition, we systematically identify linkages in the course of the entrepreneurship process, and we suggest stress theories to assist future research. The insights developed here cumulate in a morphological box for the investigation of stress in entrepreneurship. This toolkit highlights the elements of uncertainty inherent in both the entrepreneurship process as well as the stress processes. In addition, it illustrates the incidents in the entrepreneurship process where uncertainty may initiate a stress process in entrepreneurs and where stress processes feed back into the entrepreneurship process. Thereby, we provide a novel perspective that highlights the interplay between the entrepreneurship process and stress processes. In 
addition, for each linkage the morphological box offers key concepts discussed in previous research and suggests stress theories that are most promising for addressing the interaction of entrepreneurship and stress in each particular phase in the entrepreneurial journey. Thus, our contribution is twofold. The morphological box developed here not only summarizes key insights of past research at the entrepreneurship/stress interface. It also offers orientation and guidance for future research as well as key concepts and powerful theories to build on. Employing the tools provided in the morphological box for research on entrepreneurial stress will lead to research findings that are more consistent and conclusive in the future. Finally, we critically reflect on the challenges implied by the development of the new research area proposed. We believe that the results will change the way scholars examine and understand stress in entrepreneurship and how they investigate individual-level contingencies in the entrepreneurial process.

\section{THE ENTREPRENEURSHIP PROCESS AND STRESS PROCESSES}

Both entrepreneurship and stress research introduced process models. Process models try to explain how and why processes unfold over time (Van de Ven, 1992). For instance, 32 alternative models of the entrepreneurship process were identified and discussed in a comprehensive review (Moroz \& Hindle, 2012). Most of them apply event based process models. In such event-based models, variables explaining one part of the entrepreneurial process do not necessarily explain other parts of the process. This implies that the entrepreneurial process might not necessarily result in a new business venture. One of the most influential process models is the opportunity-driven new means-end framework (Shane, 2003; Shane \& Venkataraman, 2000). It conceptualizes the entrepreneurial process as consisting of the recognition and exploitation of opportunities and their associated outcomes. Entrepreneurial opportunities are situations in which entrepreneurs introduce and sell new 
goods, services, raw materials, and organizing methods at a value greater than their cost of production. Thus, opportunities exist in an objective sense (Shane \& Venkataraman, 2000). Whether these opportunities materialize in the emergence of an organization (i.e., opportunity exploitation) depends to a large extent on entrepreneurs' perceptions and interpretations of opportunities (i.e., opportunity exploration) and resources available in the environment (Edelman \& Yli-Renko, 2010). Finally, the actions of the entrepreneur and the environment determine the outcomes of opportunity exploitation (Gartner \& Carter, 2003). The model combines individual and environmental elements of the entrepreneurial process.

Stress is associated with environmental demands and the individuals' interpretation and reactions to these demands. Thus, this model of the entrepreneurship process is particularly useful to combine with stress processes. Like entrepreneurship, stress is a process that evolves over time. Many conceptualizations of stress processes are outcome based, that is, they try to predict the consequences of stress processes. There are a number of competing stress process models available in the literature. Many of them assume that there are some sources of stress, mediating processes, and outcomes of stress processes. For example, McGrath (1970) distinguishes four stages of the stress process. The process starts with situational demands (stressors) that include physical, psychological, or cognitive demands. However, the mere existence of demands does not necessarily result in stress. The experience of stress depends on people's perceptions of demands and their capabilities to deal with such demands. In other words, an identical situation can be stressful for one person but not for another. Depending on this cognitive appraisal, the stress process might generate a stress reaction (strain). Finally, the stress reaction may influence a number of behavioral results, including performance. For example, stress reactions reduce entrepreneurs' informationprocessing capabilities, which in turn affect the performance of the firm. 
We next identify and describe the linkages between the entrepreneurial process and the stress process.

\section{UNCERTAINTY LINKING THE ENTREPRENEURSHIP PROCESS AND THE UNDERLYING STRESS PROCESSES}

The concept of uncertainty provides the link between the entrepreneurial process and stress processes. Uncertainty constitutes a conceptual cornerstone in most theories of the entrepreneur (McMullen \& Shepherd, 2006, p. 132). Although there are different definitions in the literature, a general definition of uncertainty refers to the individual's perceived inability to predict something accurately (Milliken, 1987). A core task of entrepreneurs is to reduce this uncertainty. Often, entrepreneurs, in contrast to other people, can reduce this uncertainty to the extent that is required to recognize and exploit opportunities to achieve associated outcomes. However, reducing uncertainty is difficult as uncertainty inhibits actions (McMullen \& Shepherd, 2006). Moreover, uncertainty is detrimental for entrepreneurial activity because it creates doubts, resistance, indecisiveness, and procrastination (Casson, 1982). One study empirically confirms the notion that uncertainty decreases the entrepreneur's willingness to take action (McKelvie, Haynie, \& Gustavsson, 2011). However, by not taking actions and reducing uncertainty, failure and severe stress reactions might occur. Nonetheless, many entrepreneurs succeed in reducing uncertainty. Both the stress literature and the entrepreneurship literature provide overlapping explanations on how this happens.

In the entrepreneurship literature, we find several individual-level explanations as to how entrepreneurs reduce uncertainty. These explanations focus on the role of knowledge and motivation. Knowledge reduces uncertainty; people with more knowledge and information have more accurate perceptions about opportunities and thus avoid the ignorance created by uncertainty (Shane \& Venkataraman, 2000). Motivation, in this context, refers to the ability of 
individuals to bear uncertainty (McClelland \& Winter, 1971; Schumpeter, 1935). Motivation and knowledge affect the entire entrepreneurial process and interact with situational demands. Thus, the uncertainty associated with opportunity recognition, exploitation, and anticipated outcomes depends on the entrepreneur and the environment.

Uncertainty is also a key antecedent of stress processes creating demands on the individual. For example, an information-theoretical approach to stress assumes that stress originates in uncertainty (Mason, 1968). According to this approach, people make causal inferences about which strategy they should select in order to achieve a certain outcome. Stress arises when an individual is uncertain about which strategy to select. For example, when one anticipates that outcomes will turn out to be something other than expected. People have adaptive responses to stress (McGrath, 1970). For example, the better they adjust their beliefs about uncertainty, the better they are able to predict future outcomes, thus reducing stress resulting from uncertainty. However, when the uncertainty becomes chronic and cannot be reduced it leads continuous and ineffective physiological stress reactions that cause depression, cognitive impairment, infarction, and stroke in the long term (Peters \& McEwen, 2015).

According to an information-theoretical approach, reducing uncertainty requires cerebral energy. If the brain does not succeed in reducing this uncertainty, an energy crisis emerges that impairs the memory, thereby making it even more difficult to reduce uncertainty (Peters et al., 2017). Three mechanisms help reduce individuals' uncertainty: attention, learning, and habituation (Peters et al., 2017). First, attention is an immediate reaction to uncertainty. Attention increases the arousal required to retrieve more precise information cues from memory and allows a better prediction of outcomes. Second, the brain learns the precision of prediction errors, allowing it to discriminate between credible and imprecise 
information. Finally, habituation occurs when people experience uncertainty. Moreover, there are individual differences in habituation that are, in part, genetically determined.

Although originating from very different disciplines, both entrepreneurship and stress scholars propose quite similar mechanisms for reducing uncertainty. Specifically, both emphasize the role of information, learning, and attention on the one hand and motivation and habituation on the other hand. We conclude that these shared mechanisms for reducing uncertainty closely link the entrepreneurial process to the stress process. Thus, we argue that underlying stress processes affect the entrepreneurial process. The entrepreneurial process involves specific challenges associated with opportunity recognition, exploitation, and associated outcomes. Each of these challenges demand critical decisions, actions, and outcomes (Shepherd \& Patzelt, 2017). The underlying stress processes affect these critical decisions, actions, and outcomes. In turn, entrepreneurs' decisions, actions, and outcomes affect the stress processes in both positive and negative ways. In the following, we interlink each part of the entrepreneurial process with the stress process. Specifically, we focus on opportunity recognition, opportunity exploitation, and associated outcomes.

\section{The Entrepreneurial Process as Affected by Stress Processes: Key Situations}

The recognition of opportunities. The definition of opportunities introduced above (Shane \& Venkataraman, 2000) implies that whether or not a situation is an opportunity cannot be predicted beforehand. Therefore, the recognition of opportunities implies high uncertainty. Specifically, the uncertainty associated with this initial part of the entrepreneurship process is what Milliken (1987) refers to as state uncertainty. State uncertainty is the difficulty of predicting how the components of the environment are changing. Opportunities present themselves through different loci of changes (Eckhardt \& Shane, 2003). Such changes are 
difficult to predict. Accordingly, the recognition of opportunities is associated with uncertainty.

To our knowledge, entrepreneurship research has not addressed the link between stress and opportunity recognition in. Most researchers agree that the recognition of opportunities is, to a large extent, dependent on cognitive processes including prior knowledge (Shane, 2000) and mental structures such as alertness (Gaglio \& Katz, 2001). While prior knowledge is a central cognitive resource in the opportunity identification process, mental structures provide a framework representing some aspects of the world. This provides a system of organizing and perceiving new information and retrieving information previously stored in memory. Opportunity recognition is related to four mental structures: higher-ordered structural alignment, prototype models, alertness, and creativity. Higher-ordered structural alignment strives to find similarities between new information and the contexts in which this information is meaningful (Grégoire, Barr, \& Shepherd, 2010). Prototype models provide idealized representations of categories which assist in comparing ideas for new products, services, and processes with the existing prototype of an opportunity (Baron \& Ensley, 2006). Alertness, that is, complex and adaptive mental schemas about change, industries, and social environments, allows situations to be seen in new and unconventional ways (Gaglio \& Katz, 2001). Finally, creativity promotes the generation and implementation of new ideas (Amabile, 1988). While the link between cognition and opportunity recognition is widely established, the role of stress in this process is unknown.

Importantly, the stress literature provides ample evidence that stress affects cognition (Lupien, McEwen, Gunnar, \& Heim, 2009). Therefore, stress should affect opportunity recognition as well. In general, stress reduces the ability to process information (Ellis, 2006). In entrepreneurship, this is the information required to understand what is going on in the context of the opportunity. As a result, high levels of stress enhance individuals' perceived 
uncertainty associated with opportunity recognition. In this respect, it is useful to distinguish between the explicit and the implicit memory. The explicit memory requires the conscious and intentional collection and processing of factual information requiring complex and flexible reasoning. Such reasoning is typically observed for hippocampus and prefrontal cortex-related functions (Sandi, 2013). Explicit memory is required to recognize large opportunity sets. Such opportunity sets have been related to long-term superior business performance and growth (Gruber, MacMillan, \& Thompson, 2008). However, both acute and chronic stress negatively influence information-processing capacity as they reduce an individual's breadth of attention (see, e.g., Ellis, 2006). Consequently, stressed individuals may be less able to increase their knowledge and to apply higher-ordered structural alignment skills. This, in turn, may hinder the recognition of opportunities in general.

Notably, stress research shows that high stress enhances the performance of implicit memory and well-rehearsed tasks. Sandi (2013) observed this effect for amygdala-dependent conditioning tasks and for striatum-related processes. The implicit memory helps perform tasks without conscious awareness. Therefore, stressed individuals may be better able to perceive relationships between seemingly independent events and trends and to uncover emergent patterns in these relations (Baron \& Ensley, 2006). Thereby, they make better use of their pattern recognition skills, which depend on experience. Thus, there seem to be positive as well as negative effects of stress on brain functioning.

It is important to note that several approaches such as activation theory (Gardner, 1990) and the Yerkes Dodson law (Yerkes \& Dodson, 1908) suggest an inverted U-shaped function between stress intensity and cognitive functioning. An inverted U-shaped function is well established in creativity research. For instance, meta-analytic results reveal that stress can enhance creative and imaginative action only if the associated activation is at a moderate level (Byron, Khazanchi, \& Nazarian, 2010). This is because moderate activation is related to 
effective use of short-term memory, sustained information transfer within memory, and maximum use of rehearsal and storage of task-relevant information (Humphreys \& Revelle, 1984). Studying the effects of cognitive processes such as alertness and pattern recognition in conjunction with stress will likely reveal new theoretical insights into opportunity recognition processes.

Given the assumed linkages between stress and the entrepreneurial process, we further suggest that opportunity recognition should also affect stress. In this regard, it is useful to draw on the differentiation between third-person opportunity and first-person opportunity (McMullen \& Shepherd, 2006). In the first case, the individual believes that the opportunity he or she recognizes exists for someone (i.e., third-person opportunity), but not for everyone — only for those with the right qualities. Stress should not affect such an abstractbecause it is not first-person centered-belief. According to the transactional model of stress (Lazarus \& Folkman, 1984), stress results from the individual's appraisal of the stressor (primary appraisal: "whether there is something at stake") and from the social and cultural resources at his or her disposal (secondary appraisal: "what can be done about it"). If the individual believes that there is an opportunity for someone, then there is nothing at stake. "In essence, believing that a third-person opportunity exists does not necessarily mean that one believes one possesses the right combination of knowledge and motivation to exploit it" (Tang, Kacmar, \& Busenitz, 2012, p. 80). Thus, stress reactions are rather unlikely. With regard to the second case, recognizing a third-person opportunity can activate an evaluation process where the entrepreneur has to decide whether the opportunity is a first-person opportunity (Tang et al., 2012), that is, an opportunity for him or her. Depending on the individual's motivation, this evaluation process leads to stress. For example, prior research has differentiated between opportunity-driven entrepreneurs who are motivated by the desire to pursue an interesting opportunity, and necessity-driven entrepreneurs for whom 
entrepreneurship is often the best, but not necessarily the preferred, occupation (Bosma \& Levie, 2009). For the latter, the recognized opportunity needs to constitute a first-person opportunity, or an engagement in entrepreneurial action critical to secure income will not be possible. However, as necessity entrepreneurs typically have few resources, recognizing the opportunity as a first-person opportunity can be expected to result in stress (Edwards, 1992). We believe that there are many opportunities in studying stress in relation to opportunity recognition. For example, Shane (2000) argued that opportunity recognition depends on knowledge and that one can systematically search for opportunities (Fiet, Piskounov, \& Patel, 2005). Thus, opportunity recognition depends on explicit memory and conscientious processing. This means that stress intensity and information load cannot be too high. For example, opportunities that require well-established knowledge structures, such as high technology products, might be negatively related to stress processes. Other scholars argue that people recognize opportunities based on heuristics and mental schemes because the uncertainty is associated with unpredictable changes in the environment (Baron, 2003), and thus rely on implicit memory. This also might explain why Kirzner (1997) argues that entrepreneurs often recognize opportunities in a "eureka" experience. This approach would suggest that stress is particularly important to recognize narrower opportunity sets. Stress promotes the use of cognitive strategies that imply a more narrow attentional focus.

Therefore, entrepreneurs might rely on cognitive frameworks that serve as focused guides and templates. It might be interesting to see whether stress intensity associated with uncertainty explains the variance in these two different modes of opportunity recognition.

The exploitation of opportunities. Recognition of an opportunity is a necessary but not sufficient condition for entrepreneurship. Once an opportunity has been recognized as such, one has to decide whether to exploit the opportunity. The exploitation of opportunities follows 
a volitional decision to translate entrepreneurial intention into action (Van Gelderen,

Kautonen, \& Fink, 2015). Opportunity exploitation is associated with uncertainty.

Specifically, this is the inability to predict the impact of a future state of the environment on the new organization. According to Milliken (1987), this is effect uncertainty. For example, people who start a business venture face the liability of newness involving low legitimacy, limited resources, restricted control, and a lack of constructive feedback (Aldrich \& Fiol, 1994). Since such liabilities are due to market characteristics, they are, in part, beyond the control of the individual entrepreneur, and thus cause uncertainty and stress. Therefore, it is important to understand the processes that enable entrepreneurs to reduce the uncertainty associated with opportunity exploitation to an extent that allows them to proceed with the entrepreneurial process.

Given this situation, most classical stressor-strain-outcome models predict that entrepreneurs who start exploiting opportunities face high uncertainty. Accordingly, they experience high stress and, thus, display high stress reactions such as psychosomatic complaints, exhaustion, and ill health (Koeske \& Koeske, 1993). This positive relationship between stressors and stress reactions is well validated in organizational behavior and is true for both challenge and hindrance stressors (Lepine, Podsakoff, \& Lepine, 2005). However, when we quantify the empirical studies included in this exposition ${ }^{1}$, we find little evidence supporting the proposition that stress processes affect entrepreneurs. For example, studies examining whether entrepreneurs face more stressors than non-entrepreneurs exhibit a weighted correlation of $r=-.011^{2}$ (ns., $k=7$ studies). Moreover, entrepreneurs seem to show less stress reactions than non-entrepreneurs do (weighted $r=-.053, p<.05, k=13$ ).

Therefore, it is necessary to investigate why well-established relationships in organizational behavior do not apply in the entrepreneurial process. From an entrepreneurship perspective,

\footnotetext{
${ }^{1}$ The studies included in these analyses are marked with an asterisk in the reference section.

${ }^{2}$ We translated the mean difference into the $r$ statistic here.
} 
entrepreneurs exploiting opportunities take actions that help to reduce the uncertainty associated with opportunity exploitation. Several frameworks explain how entrepreneurs accomplish this.

First, the attraction-selection-attrition (ASA) framework (Schneider, Goldstein, \& Smith, 1995) can explain why entrepreneurs experience less stress when exploiting opportunities. ASA theory predicts that some people are attracted to entrepreneurship because they feel that that their personal skills, characteristics, and motives are in alignment with the tasks associated with entrepreneurship. Moreover, those who actually find that they are suited to entrepreneurship will choose to enter this area. Finally, those who discover that their skills, characteristics, or interests do not align closely with the requirements of entrepreneurship withdraw from it, either voluntarily or otherwise. As a result, those who exploit opportunities are less vulnerable to stress reactions (Baron et al., 2016). Two mechanisms explain this outcome. First, knowledge and information are core characteristics that enable people to become entrepreneurs (McMullen \& Shepherd, 2006) as they allow the development of better predictions, and, therefore, reduce both uncertainty and stress. Thus, people who process more knowledge and information are more likely to be attracted to and select into entrepreneurship. Second, psychological capital is defined as a positive stage of an individual consisting of selfefficacy, optimism, hope, and resilience (Luthans, Avolio, Avey, \& Norman, 2007). It has been related to a number of outcome variables in organizational behavior research, one of which is reduced stress (Avey, Reichard, Luthans, \& Mhatre, 2011). Therefore, psychological capital provides an effective buffer against high levels of stressors experienced in opportunity exploitation. One study reports that psychological capital is negatively related to entrepreneurs' levels of perceived stress (Baron et al., 2016). Such individual-level characteristics are likely more important at the beginning of the entrepreneurial process than during the later stages (Przepiorka, 2016). 
A second approach would suggest applying a contingency framework to stress and opportunity exploitation. For example, the job-demand-control model (Karasek, 1990) assumes that stress reactions stem from the interaction between job demands and control over those demands. Job demands refer to the work intensity a person experiences, which typically manifests in issues such as workload, time pressure, and conflicting demands. Overwhelming demands are likely to lead to a negative appraisal as, for example, conflicts between old and new roles emerge (Wincent \& Ortqvist, 2009) and the venture lacks established routines and procedures. Thus, it is evident that opportunity exploitation is associated with high demands. However, many entrepreneurs find such situational demands attractive and motivating rather than threatening (Cardon, Foo, Shepherd, \& Wiklund, 2012). High control allows perceiving such demands as positive challenges. Control refers to decision latitude. Entrepreneurs have high control because they decide to exploit a business opportunity. Thus, the model asserts that there will be interactive effects of demands and control on stress reactions. Specifically, the combination of high demands (both physical and psychosocial) and high control is typical in opportunity exploitation and does not result in stress reactions. This argument is empirically supported by Stephan and Roesler (2010).

Stress processes can also affect the decision to exploit a business opportunity. Notably, there is a stream of research showing that some people choose entrepreneurial roles because they are not compatible with the requirements of an established organization. For example, entrepreneurship might be attractive for people with attention deficit hyperactivity disorder (ADHD), because entrepreneurship provides tasks that are characterized by fast decision making and high task variability (Wiklund, Patzelt, \& Dimov, 2016). ADHD, in turn, is associated with high stress (Drake, Riccio, \& Hale, 2017; Salla, Galéra, Guichard, Tzourio, \& Michel, 2017). Therefore, stress processes might be associated with the decision to exploit opportunities. In a similar manner, sleep deprivation prompts behavioral tendencies such as 
impulsivity, which can increase an individual's desire to start an entrepreneurial venture (Gunia, 2018). Other mental health issues related to chronic stress might stimulate entrepreneurial motives as well. One study, for example, indicated that entrepreneurs report more mental health concerns than a comparison group. Specifically, they report more depression, ADHD, substance abuse, and bipolar diagnosis (Freeman, Johnson, Staudenmaier, \& Zisser, 2015). Thus, the causal path may not only work from opportunity exploitation to stress but also the other way around: Stress may be related to the decision to exploit an opportunity and to start a business venture. To our knowledge, this issue remains unexplored in previous stress research relating to entrepreneurship.

In summary, it seems that opportunity exploitation is not related to higher stress reactions in entrepreneurs. Thus, there might be profound differences between entrepreneurs and employees. While entrepreneurs do not develop severe stress reactions, research on employees consistently indicates that job stress causes stress reactions. More research, however, is required to explore whether stress affects opportunity exploitation.

The associated outcomes. Once the enterprise is established, the situation is quite different from that in which one decides to become an entrepreneur. Therefore, we now explore whether stress processes and uncertainty are related to positive or negative outcomes of the entrepreneurial process. Potential outcomes are failure, closure, and survival (Headd, 2003), with the latter not always suggesting that firms are successful. As a matter of fact, only a small proportion of firms is successful in the sense that they grow substantially (Henrekson \& Johansson, 2010). Moreover, some firms persist in the market even though they are relatively unsuccessful (Gimeno, Folta, Cooper, \& Woo, 1997). Thus, once the firm is established, there is uncertainty, and entrepreneurs' attempts to reduce this uncertainty can result in various outcomes. Looking at outcomes involves response uncertainty (Milliken, 1987). Response 
uncertainty describes the inability to predict the likely consequences of a response choice after starting a business venture. Such uncertainty may lead to stress, which may have both positive and negative effects on outcomes. Moreover, outcomes might affect stress reactions.

With regard to the link between stress and outcomes, it is important to understand that not all theoretical approaches to stress predict a negative relationship between stressors, stress reactions, and outcomes. Some researchers have suggested an inverted U-shaped relationship between stress and performance, assuming that a moderate level of stress is most beneficial to performance. However, this hypothesis has not received strong support in the stress literature (Fay \& Sonnentag, 2002). Moreover, there are theories proposing that stress processes can have positive outcomes. Control theory (Carver \& Scheier, 1982; Edwards, 1992), for instance, predicts that stress results from discrepancies between current and desired states. Such a discrepancy leads to negative emotions and reduced well-being, and thus, to stress reactions. However, entrepreneurs aim to resolve such discrepancies by activating coping strategies. As a result, stress leads to better decisions and improved performance. Thus, according to control theory, stress has positive long-term consequences for the performance, even if stress may have caused poor performance initially. Accordingly, one study indicates that stress reduces the likelihood of firm failure after 12 years (Rauch, Unger, \& Rosenbusch, 2007). Thus, negative emotions are sometimes required to carry out entrepreneurial tasks (Hatak \& Snellman, 2017; Shepherd \& Patzelt, 2017).

The environmental context provides opportunities and sets boundaries for entrepreneurial activities (Welter, 2011). High environmental state uncertainty is unfavorable and challenging. Thus, it should increase stress reactions and negative effects on firm outcomes. However, empirical evidence shows that environmental uncertainty (high dynamism, high complexity, and low munificence) (Dess \& Beard, 1984) tends to have positive effects on firm performance (Shane \& Kolvereid, 1995; Sharfman \& Dean, 1991; 
Swaminathan, 1996). While these approaches typically explain these effects by referring to selection processes, we also know from stress inoculation research that reinterpreting stressors as challenges helps people deal with stressors. Thus, having mastered challenges in the past leads to higher competence to deal with stressors in the future (Meichenbaum \& Deffenbacher, 1988). It might be interesting for future research to clarify whether selection processes or stress inoculation processes are better suited for explaining the positive effects of environmental uncertainty on firm performance.

However, rather than stressing the positive effects of stress, most approaches in organizational behavior predict that stress and uncertainty have negative effects on outcomes. For example, stress reactions are characterized by insensitivity, indifference, and cynicism toward employees and other stakeholders (Maslach, 1982) who, in turn, reduce their commitment to and support for the entrepreneur and the firm, making a decline in firm performance likely. Moreover, prolonged stress reactions reduce entrepreneurs' capacity for the self-regulation necessary for task execution and goal attainment. Inefficient behavior and task execution reduce performance. Finally, uncertainty and associated stress reduce the ability to take action (McKelvie et al., 2011). However, active behavior is a necessary condition for firm performance. Several meta-analyses of organizational behavior reported a negative relationship between stress and performance (Abramis, 1994; Jackson \& Schuler, 1985; Swider \& Zimmerman, 2010).

In theoretical terms, the classical stressor-strain-outcome models follow the above reasoning and predict that strain is harmful to performance, because it can, for example, limit a person's regulation capacity and the ability to influence the environment and process information (Koeske \& Koeske, 1993; Lepine et al., 2005). The results in the empirical entrepreneurship literature are not that straightforward. Specifically, when quantifying the results of those studies in this paper, the relationship between stress and performance is found 
to be insignificant $(r=-.029$, ns., $k=10$ ). Thus, the negative relationship between stress and performance reported in organizational behavior is not replicated in entrepreneurship research. This indicates that there might be a third variable affecting this relationship.

Contingency theories are prominent in the stress literature (Frese, 1985) and have been applied to the entrepreneurship domain as well. Specifically, person-environment-fit approaches (Caplan, 1987) assume that the individual's ability must match the demands associated with the job. Moreover, the individual's needs must match with what the environment supplies. No match will create a higher level of psychological strain and a lower level of performance if the stimuli to which the individuals respond (e.g., workload or work complexity) are important to them. For example, demand-ability-fit implies that the entrepreneur possesses the information and knowledge required and, thus, is able to reduce the uncertainty and stress associated with the exploitation of a given opportunity. A needsupply-misfit may occur if the need to achieve becomes a cause of stress when entrepreneurs aim to achieve too much (Boyd \& Gumpert, 1983) given the resources they possess. For entrepreneurship research, this theoretical approach is attractive since it also takes into account the individual motives and capabilities—both of which are core concepts in opportunity recognition, exploitation, and associated outcomes.

Finally, associated outcomes can cause severe stress reactions among entrepreneurs. This is specifically true when they cannot reduce the uncertainty as intended. As indicated in the failure literature, these reactions can be quite severe. They include social costs and psychological costs, ranging from devaluation, stigma, shame, and grief to severe stress reactions, including physiological symptoms and depression (Ucbasaran, Shepherd, Lockett, \& Lyon, 2013). Shepherd and Wolfe (2015) use the concept of anticipated grief to characterize the negative emotions (e.g., anxiety, panic attacks, and depression) associated with firm failure, all of which are associated with stress reactions. Conservation of resources 
(COR) theory (Hobfoll, 1989) is a useful approach to explain these negative outcomes. COR is an economic theory explaining the development of strain. The theory assumes that individuals aim to obtain, retain, protect, and build (personal and external) resources, with resources being anything of value to them. Thus, increasing resources is a basic human need. Individuals invest in new resources to achieve resource gains and avoid the loss of resources. The theory connects a potential loss of resources with a negative spiral of further losses that trigger a cycle of stress reactions. According to COR, entrepreneurs with increasing resources are better off than entrepreneurs with decreasing resources are, as the latter are vulnerable to becoming trapped in loss spirals. Furthermore, the theory describes the causes of stress reactions in economic terms. Testing the theory with independent farmers indicates that financial problems cause stress reactions that in turn lead to further financial problems one year later (Gorgievski-Duijvesteijn, Giessen, \& Bakker, 2000). Therefore, in contrast to stressor-strain-outcome frameworks, the theory predicts a reverse negative path from performance to stress reactions. Notably, there is also literature, which suggests that failure is required for learning and helps entrepreneurs to pay attention to a focal task and act on it. Thus, managing failures successfully might lead to positive outcomes in the long term (Shepherd \& Patzelt, 2017). This literature is not well established and it might be interesting to focus research efforts on further investigating how much failure is tolerable for entrepreneurs to create such positive outcomes.

In summary, there are high demands associated with the outcomes of opportunity exploitation caused by high response uncertainty, resource loss, and the investment of high energy. However, these demands do not necessarily lead to negative outcomes, as there are benefits, such as being able to bear this uncertainty and having high decision latitude associated with entrepreneurship, which may outweigh the negative effects of high demands. Moreover, there are contingency variables that affect the stress-outcome relationship. The 
picture is possibly more consistent when one looks at the effects of being unsuccessful, which might imply negative effects on stress processes. Even here, however, there is some evidence indicating that previous failure leads to positive effects.

\section{BUILDING A MORPHOLOGICAL BOX TO LINK THE STRESS PROCESS WITH THE ENTREPRENEURIAL PROCESS}

Table 1 presents the three stages of the entrepreneurial process (see column 1) and the phases of the stress processes (see row 1). In the cells of the emerging matrix, we summarize (in normal type) key linkages between the entrepreneurship process and the stress processes (see row 2/column 2 to row 12/column 5). Our aim here is to present examples of such core linkages rather than provide an exhaustive list. In addition, we present the reverse mechanism describing how stress processes affect opportunity recognition, exploitation, and associated outcomes (column 6). For each of the three phases of the entrepreneurship process, we further list stress theories that may provide common ground for systematic future research on stress in entrepreneurship (column 7). While all linkages have their roots in the concept of uncertainty that is inherent in both the entrepreneurship and stress processes, the underlying stress theories each emphasize specific aspects of an entrepreneur's activity and are especially useful for specific phases of the entrepreneurship process. Accordingly, we do not understand the eight theoretical perspectives on stress as alternatives, but rather as elements in a toolkit with a sound theoretical foundation that support the coherent future development of empirical research in the field.

Table 1 here

The areas of the table that are in italics can be interpreted as a morphological box (Zwicky, 1969). This is a method originally developed in innovation management facilitating 
the development of a new field of research. By eliminating all combinations that receive no theoretical support from the grid box, this approach helps to reduce the complexity of exploring the interplay of variables potentially relevant to explain a specific phenomenon. Employing the morphological box can substantially foster and guide the development of research at the intersection of the entrepreneurial process and stress processes as a new area of research.

Generally, to fully understand a phenomenon, all configurations of relevant variables that can be underpinned by theory have to be tested empirically (Chin, 1988). Researchers wishing to develop a coherent body of knowledge at the intersection of the entrepreneurial and stress processes must first test if the theoretically linked variables in stress process theory empirically relate in the manner theoretically postulated in the different phases of the entrepreneurial process. However, depending on the selected stress theory underpinning the research, each link can take a different role in a conceptual model.

With the morphological box approach, we can reduce the high number of configurations to those that the eight stress theories underpin. This is because the eight stress process theories model each link in a specific way (i.e., not all linkages can theoretically be modeled as situational demands, appraisal, response, behavioral outcome, or reverse mechanism), and they can take only one of those roles in each model. Accordingly, in the morphological box for stress research in entrepreneurship, we find six possibilities of how to theoretically model stress processes in the entrepreneurial process. The morphological box provides guidance for coherent future research on stress in entrepreneurship.

\section{DISCUSSION}

Stress associated with work affects one in four adults, and current trends suggest that the number of adults suffering from stress-related conditions caused or made worse by work is increasing (EU-OSHA, 2014). Even though stress is evident in entrepreneurship as well, 
entrepreneurs often manage the demands associated with the entrepreneurial process successfully. These observations imply that the stress theories that originate in organizational behavior cannot simply be transferred to the entrepreneurship context. Key to our model for understanding stress is the concept of uncertainty, which provides a linkage between stress processes and the entrepreneurial process consisting of opportunity recognition, opportunity exploitation, and associated outcomes.

Resulting from uncertainty associated with opportunity recognition, stress can impair cognitive processes such as information processing which negatively affects explicit memory but may have positive effects on entrepreneurs' implicit memory. Consequently, we propose that opportunity recognition may result from unconscious awareness associated with experiences rather than from a conscious and intentional analysis of the environment. Further, we postulate that stress resulting from uncertainty can actually motivate people to start a business. This is because stress has been associated with mental health conditions, which, in turn, relate to start-up action. With regard to the uncertainty associated with opportunity exploitation, while entrepreneurs face high demands, the empirical evidence suggests that entrepreneurs have less stress reactions than non-entrepreneurs do. This might be because people who possess knowledge and psychological capital are attracted to entrepreneurship. Finally, with regard to outcomes of the entrepreneurial process, it seems that stress resulting from uncertainty can lead to both positive and negative outcomes. Especially in the long run, entrepreneurs are likely to develop strategies to cope with stress, which has positive implications for performance, even if stress may have led to poor performance initially.

\section{Theoretical and Practical Contribution}

Out theorizing suggests important implications for the field of entrepreneurship. First, by connecting the entrepreneurial process with the stress process via the concept of 
uncertainty, we developed an individual level approach to entrepreneurship. The importance of the concept of uncertainty has been acknowledged in the decision-making context and in the context of actions reducing uncertainty. This theorizing focused on outcomes on the level of the firm. Other approaches discussed uncertainty with regard to markets and economies. Our approach highlights that uncertainty has positive and negative consequences for the individual entrepreneur and shows that uncertainty at the level of the individual entrepreneurs is ultimately associated with stress. Failing to account for underlying stress processes associated with uncertainty may lead to misspecified theories and spurious relationships.

Second, our approach suggests reciprocal relationships between stress processes and the entrepreneurial process. Most entrepreneurship theorizing has argued for one dominant causal path, specifically, that uncertainty affects individuals' decisions, actions, and outcomes (McMullen \& Shepherd, 2006). In contrast, the stress literature in entrepreneurship has emphasized the other causal path from the entrepreneurial process to stress, for example, in studies looking at whether or not entrepreneurs experience more stress reactions than nonentrepreneurs do. Our review concludes, however, that the causal path works in both ways: Stress and uncertainty affect the entrepreneurial process, and the entrepreneurial process affects uncertainty and stress. The concept of uncertainty allows connecting both causal paths in a dynamic way. For example, stress might be a consequence of entrepreneurial action but it might also lead to recognizing opportunities and for the decision to exploit an opportunity (compare above). Thus, we argue that entrepreneurship may provide opportunities for people who otherwise would have difficulties working in an established organization. In addition, there is some indication that stigmatization resulting from failure can, in some contexts, stimulate entrepreneurial behavior (Simmons, Wiklund, \& Levie, 2014). Finally, we argue that stress can have positive outcomes in the long term. Thus, we think that there are ample opportunities to look at how stress can facilitate entrepreneurship and vice versa. Moreover, 
the entrepreneurial process is dynamic and involves feedback loops (Frese, van Gelderen, \& Ombach, 2000). For example, depending on the outcome of the evaluation of an opportunity, entrepreneurs either exploit this opportunity and start reducing uncertainty or continue searching for opportunities (Ropo \& Hunt, 1995).

Moreover, in the later stages of the entrepreneurial process, unsuccessful exploitation encourages entrepreneurs to adjust or abandon the serving business model. Thus, the outcomes of stress reactions affect the entrepreneurial process. The feedback changes the values for the next iteration in the stress process. Accordingly, the stress process becomes circular and self-reinforcing (Selye, 1957). That situation arises if stress reactions lead to reduced performance, which implies a resource loss that in turn triggers further stress reactions. Such feedback loops are in line, for example, with the COR approach, control theory, and the transactional model of stress, and have been identified in organizational behavior (Fay \& Sonnentag, 2002) as well as in the entrepreneurship domain (GorgievskiDuijvesteijn et al., 2000). Thus, when researching the linkages between the entrepreneurial process and stress processes, a dynamic perspective is imperative.

Additionally, the challenging stimuli that entrepreneurs perceive over the course of the entrepreneurship process change substantially, implying that the stress processes and their effects differ across different stages of the entrepreneurship process. However, most previous studies report snapshots from different phases of the entrepreneurial process. For example, while the study by Rauch (2014) focuses on relatively new enterprises in the firm formation phase, other studies do not focus on any specific phase of the entrepreneurial process (e.g., Jamal, 1997).

A third contribution refers to contingencies affecting both the stress process and the entrepreneurial process. Stress-related contingencies might be one reason why effect sizes reported in meta-analyses conducted in the domain of entrepreneurship are heterogeneous 
and, thus, not generalizable (Frese, Bausch, Schmidt, Rauch, \& Kabst, 2012). These effect sizes can be attributed to the fact that firm performance and competitive advantage are unstable and affected by causal and complex issues surrounding performance (March \& Sutton, 1997). In addition, the majority of contingency studies in entrepreneurship research focus on the external environment in which the entrepreneur's firm is embedded (environmental uncertainty). However, the current research indicates that scholars questioning how stress processes influence the entrepreneurship process should also consider individuallevel contingencies such as perceptions of low control as a core variable of the job-demandcontrol model. Such, contingency variables help to disentangle the discussion of whether entrepreneurs suffer from more severe stress reactions than other groups in the working population.

Finally, the results of this review may also have practical implications for a broader context. For example, Hajkowicz (2015) discusses seven patterns of global change that provide powerful trajectories of change that have the potential to throw companies, individuals, and societies into freefall. These megatrends include, for example, technological changes, demographic changes, the way people and companies interact in a globalized world, and the difficulties of ensuring resource security. Such trends may very well create uncertainty and stress, thereby creating challenges for individuals, organizations, and societies. Our review provides some suggestions as to how to address these challenges at the individual level. For example, individuals must be encouraged to perceive such challenges as opportunities that one may take advantage of. Our review reveals that knowledge, learning, and information, as well as motivation and habituation, the latter being also related to psychological capital, are critical factors dealing with uncertainty and stress. Such factors might be enhanced, for example, by reassessing educational priorities or incorporating change into educational curricula. In turn, we need a research agenda examining what helps 
individuals to set off into venturing, entrepreneurship, and intrapreneurship. Entrepreneurs are agents of change and, as our review indicates, they are able to reduce uncertainties in opportunity recognition, opportunity exploitation, and outcomes. We must examine critically whether the nature of entrepreneurship can transfer to other non-business contexts, thus enabling societies to deal with the megatrends described by Hajkowicz (2015).

\section{Future Research}

The review highlights further areas for future investigation. First, there are blind spots that, to our knowledge, prior research has not addressed. For example, prior research has studied stress of established entrepreneurs and the relationships between stress and outcomes. However, research on the relationship between opportunity recognition and stress is missing. Such research would be relevant to the field because stress and uncertainty are likely to affect cognition and, thereby, the type of opportunity recognized. In turn, opportunity recognition will affect uncertainty and stress. In addition, an area that needs more attention is the relationship between stress and opportunity exploitation. There is an emerging stream of research looking into mental health conditions and opportunity exploitation (Wiklund, Hatak, Patzelt, \& Shepherd, 2018). Stress, if not correctly managed, can be a trigger for many mental health problems such as burnout, depression, and other delayed stress reactions. Therefore, it may be useful to examine stress among entrepreneurs. Moreover, entrepreneurship could function both as a way to manage stress in order to avoid such chronic reactions, and as a way to reduce stigmatization associated with chronic stress reactions and impaired mental health.

Second, the majority of studies on the stress processes of entrepreneurs examine isolated aspects of the stress process. For example, they look at whether entrepreneurs face more stress or whether they display more stress reactions. In a similar manner, many stress theories can only map parts of the entrepreneurial process (compare morphological box). 
However, we think that it is important to link the two processes to each other in order to provide a more consistent picture. As such, research results strongly depend on the point in the entrepreneurship process at which researchers collect the data. Failing to account for such process-related changes in the independent and dependent variables might explain conflicting results among earlier entrepreneurship studies. There are two options to tackle this problem. First, researchers should avoid broadband samples such as comparing any self-employed person with other occupations. While there is a long-standing discussion in entrepreneurship research about the definition of the entrepreneur (Gartner, 1985), our review reinforces calls for researchers to care more about their samples as stress processes have different meanings at different stages in the entrepreneurial process. A second option to address the process is to collect longitudinal data. Researchers should measure the relevant factors discussed above several times in order to obtain a fine-grained picture of how the stress processes unfold in the course of the entrepreneurial process. Capturing a clearer picture of entrepreneurs and their embeddedness in the ever-changing context throughout the entrepreneurship process and the stress processes would also likely reduce the (unobserved) heterogeneity in the samples and have a positive effect on the robustness, generalizability, and comparability of the findings. Up-and-coming data collection strategies such as smartphone apps or gamification might help to meet this challenge and still collect a sufficient number of observations. The use of technology devices capturing entrepreneurs' heart rates and galvanic skin responses in conjunction with experience sampling methods has the potential to yield relevant findings. In short, our morphological box provides a toolkit for researchers and suggests that future research should focus on aligning stress processes and the entrepreneurial process more closely. Moreover, we suggest several relevant theories with regard to the specific research aims. 


\section{Conclusion}

In order to drive innovation, change, and economic growth, societies and economies rely on entrepreneurs who can successfully develop and run ventures (Block, Fisch, \& van Praag, 2017). By venturing into the unknown, entrepreneurs experience high uncertainty (Knight, 1921). At the same time, high uncertainty is a core antecedent of stress. Thus, entrepreneurship affects stress processes. Stress, in turn, affects entrepreneurship, as it influences the recognition and exploitation of business opportunities as well as the outcomes of the entrepreneurial process such as performance and growth. By identifying uncertainty as the nexus between the entrepreneurial process and the underlying stress processes, our exposition provides the basis for a more complete and specific understanding and modeling of the role of stress in entrepreneurship. Our morphological box provides researchers a valuable toolkit to aid future progress in knowledge accumulation at the intersection of entrepreneurship and stress. 
TABLE 1

Morphological Box: Linkages Between Entrepreneurship Process and Stress Processes

\begin{tabular}{|c|c|c|c|c|c|c|c|}
\hline & & \multicolumn{5}{|l|}{ STRESS PROCESSES $\rightarrow$} & \multirow{2}{*}{$\begin{array}{l}\text { Stress theories linking the } \\
\text { entrepreneurship and stress } \\
\text { processes }\end{array}$} \\
\hline & & Situational demands & Appraisal & Response & Behavioral outcomes & Reverse mechanism & \\
\hline \multirow{8}{*}{ 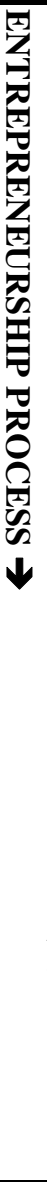 } & \multirow[t]{3}{*}{$\begin{array}{l}\text { Opportunity } \\
\text { recognition }\end{array}$} & $\begin{array}{l}\text { High demands } \\
\text { Mainly state uncertainty }\end{array}$ & $\begin{array}{l}\text { Mental structures } \\
\text { Knowledge } \\
\text { Information }\end{array}$ & $\begin{array}{l}\text { Impaired explicit memory, } \\
\text { creativity } \\
\text { Improved implicit memory } \\
\text { Reduced information } \\
\text { processing }\end{array}$ & $\begin{array}{l}\text { Reduced/increased ability to } \\
\text { recognize large/narrow opportunities } \\
\text { sets }\end{array}$ & $\begin{array}{l}\text { Translating third-person } \\
\text { opportunity into first-person } \\
\text { opportunity }\end{array}$ & \\
\hline & & Entropy as stressor & $\begin{array}{l}\text { Assessment of } \\
\text { noise in the } \\
\text { communication } \\
\text { channel }\end{array}$ & $\begin{array}{l}\text { Learning, habituation, } \\
\text { attention }\end{array}$ & Performance & $\begin{array}{l}\text { Successful past } \\
\text { communication is } \\
\text { information for next } \\
\text { communication }\end{array}$ & $\begin{array}{l}\text { Information theory (Shannon, } \\
\text { 1948) }\end{array}$ \\
\hline & & Source of stressor & $\begin{array}{l}\text { Source of } \\
\text { activation }\end{array}$ & $\begin{array}{l}\text { Memory, information } \\
\text { transfer, mental structures }\end{array}$ & Performance & $\begin{array}{l}\text { Performance impacts on } \\
\text { activation level }\end{array}$ & $\begin{array}{l}\text { Activation theory (Gardner, } \\
\text { 1990) }\end{array}$ \\
\hline & \multirow[t]{3}{*}{$\begin{array}{l}\text { Opportunity } \\
\text { exploitation }\end{array}$} & $\begin{array}{l}\text { Demands } \\
\text { Mainly effect and response } \\
\text { uncertainty } \\
\text { Lack of experiences/routines } \\
\text { Resource constraints } \\
\text { Liabilities }\end{array}$ & $\begin{array}{l}\text { Attraction based } \\
\text { on: Motivation, } \\
\text { knowledge, } \\
\text { psychological } \\
\text { capital, } \\
\text { control }\end{array}$ & $\begin{array}{l}\text { Selection } \\
\text { Learning }\end{array}$ & Venture creation and attrition (exit) & $\begin{array}{l}\text { Increased stress associated } \\
\text { with mental health, ADHD, } \\
\text { and sleep deprivation might } \\
\text { affect exploition }\end{array}$ & \\
\hline & & Source of demands & Source of control & $\begin{array}{l}\text { Strain in case resources do } \\
\text { not meet the demands }\end{array}$ & Performance & $\begin{array}{l}\text { Past performance impacts } \\
\text { future levels of demands } \\
\text { and control }\end{array}$ & $\begin{array}{l}\text { Job Demands Control model } \\
\text { (Karasek, 1979) }\end{array}$ \\
\hline & & Source of attraction & $\begin{array}{l}\text { Selection: Whether } \\
\text { or not to size an } \\
\text { opportunity }\end{array}$ & rReduced levels of stress & Performance & $\begin{array}{l}\text { Selection leads to exit or } \\
\text { upward spiral }\end{array}$ & $\begin{array}{l}\text { Attaction, selection, attrition } \\
\text { framework (Schneider et al., } \\
\text { 1995) }\end{array}$ \\
\hline & \multirow[t]{2}{*}{$\begin{array}{l}\text { Associated } \\
\text { outcomes }\end{array}$} & $\begin{array}{l}\text { Mainly response uncertainty, } \\
\text { Resource loss } \\
\text { Failure vs. survival } \\
\text { Discrepanciese between current } \\
\text { and anticipated outcomes } \\
\text { Person environment fit }\end{array}$ & $\begin{array}{l}\text { Coping, } \\
\text { Selection } \\
\text { Self-regulation }\end{array}$ & $\begin{array}{l}\text { Inocculation } \\
\text { Reduced action } \\
\text { Decisions/ } \\
\text { Ability to adjust }\end{array}$ & $\begin{array}{l}\text { Success } \\
\text { Failure } \\
\text { Survival }\end{array}$ & $\begin{array}{l}\text { Failure and resource loss } \\
\text { causes negative emotions, } \\
\text { grief and loss spirals }\end{array}$ & \\
\hline & & Source of stressor & - & Strain & Performance & - & Stressor-strain-outcome models \\
\hline
\end{tabular}




\begin{tabular}{|c|c|c|c|c|}
\hline Source of discrepancy & $\begin{array}{l}\text { Source of coping Strain } \\
\text { strategy }\end{array}$ & Performance & $\begin{array}{l}\text { Past performance impacts } \\
\text { on current discrepancy }\end{array}$ & $\begin{array}{l}\text { Control theory (Carver \& } \\
\text { Scheier, 1982) }\end{array}$ \\
\hline Source of stressor & Assessment of fit Strain & Performance & $\begin{array}{l}\text { Stressor (moderators of } \\
\text { effects) }\end{array}$ & $\begin{array}{l}\text { Contingency theories (Edwards, } \\
\text { Caplan, \& Harrison, 1998) }\end{array}$ \\
\hline Area of activation & Area of activation Firm performance & Strain & $\begin{array}{l}\text { Resource loss is stressor } \\
\text { (downward spiral) }\end{array}$ & $\begin{array}{l}\text { Conservations of Resources } \\
\text { theory (Hobfoll, 1989) }\end{array}$ \\
\hline
\end{tabular}




\section{REFERENCES}

Abramis, D. J. (1994). Work role ambiguity, job satisfaction, and job performance: Meta-analyses and review. Psychological Reports, 75(3 suppl), 1411-1433. doi:10.2466/pr0.1994.75.3f.1411

Aldrich, H. E., \& Fiol, C. M. (1994). Fools rush in? The institutional context of industry creation. The Academy of Management Review, 19(4), 645-670. doi:10.2307/258740

Amabile, T. M. (1988). A model of creativity and innovation in organizations. Research in Organizational Behavior, 10, 123-167.

Avey, J. B., Reichard, R. J., Luthans, F., \& Mhatre, K. H. (2011). Meta-analysis of the impact of positive psychological capital on employee attitudes, behaviors, and performance. Human Resource Development Quarterly, 22(2), 127-152. doi:10.1002/hrdq.20070

Baron, J. A., \& Ensley, M. D. (2006). Opportunity recognition as the detection of meaninful Patterns: Evidence from comparisons of novice and experienced entrepreneurs. Management Science, 52(9), 1331-1344.

Baron, R. A. (2003). Cognitive foundations of opportunity recognition: Identifying the opportunity prototypes of repeat entrepreneurs. Presented at: Babson College-Kaufman Foundation Research Conference, Babson, 4-7 June.

* Baron, R. A., Franklin, R. J., \& Hmieleski, K. M. (2016). Why entrepreneurs often experience low, not high, levels of stress: The joint effects of selection and psychological capital. Journal of Management, 42(3), 742-768. doi:10.1177/0149206313495411

Block, J. H., Fisch, C. O., \& van Praag, M. (2017). The Schumpeterian entrepreneur: a review of the empirical evidence on the antecedents, behaviour and consequences of innovative entrepreneurship. Industry and Innovation, 24(1), 61-95.

doi:10.1080/13662716.2016.1216397 
Bosma, N., \& Levie, J. (2009). Global Entrepreneurship Monitor: 2009 Executive Report. http://www.gemconsortium.org/.

Boyd, D. P., \& Gumpert, D. E. (1983). Coping with entrepreneurial stress. Harvard Business Review, 61(2), 44-64.

Byron, K., Khazanchi, S., \& Nazarian, D. (2010). The relationship between stressors and creativity: A meta-analysis examining competing theoretical models. Journal of Applied Psychology, 95(1), 201-212. doi:10.1037/a0017868

Caplan, R. D. (1987). Person-environment fit theory and organizations: Commensurate dimensions, time perspectives, and mechanisms. Journal of vocational behavior, 31(3), 248-267. doi:http://dx.doi.org/10.1016/0001-8791(87)90042-X

* Cardon, M. S., \& Patel, P. C. 2015. Is stress worth it? stress-related health and wealth trade-offs for entrepreneurs. Applied Psychology, 64(2), 379-420. doi:10.1111/apps.12021

Cardon, M. S., Foo, M.-D., Shepherd, D., \& Wiklund, J. (2012). Exploring the heart: Entrepreneurial emotion is a hot topic. Entrepreneurship Theory and Practice, 36(1), 1-10. doi:10.1111/j.1540-6520.2011.00501.x

Carver, C. S., \& Scheier, M. F. (1982). Control theory: A useful conceptual framework for personality - social, clinical, and health psychology. Psychological bulletin, 92, 111-135.

Casson, M. (1982). The entrepreneur: An economic theory. Totowa and NJ: Barnes and Noble Books.

Chin, W. W. (1988). The partial least squares approach to structural equation modeling. In G. A. Marcoulides (Ed.), Modern methods in business research (pp. 295-336). Hillsdale: Earlbaum.

Dess, G. G., \& Beard, D. W. (1984). Dimensions of organizational task environments. Administrative Science Quarterly, 29, 52-73. 
* Dijkhuizen, J., Gorgievski, M., van Veldhoven, M., \& Schalk, R. 2016. Feeling successful as an entrepreneur: A job demands-resources approach. International Entrepreneurship and Management Journal, 12(2), 555-573.

Drake, M. B., Riccio, C. A., \& Hale, N. S. (2017). Assessment of adult ADHD with college students. Journal of Attention Disorders, O(0), 1087054717698222. doi:10.1177/1087054717698222

Eckhardt, J. T., \& Shane, S. A. (2003). Opportunities and entrepreneurship. Journal of Management, 29(3), 333.

Edelman, L., \& Yli-Renko, H. (2010). The impact of environment and entrepreneurial perceptions on venture-creation efforts: Bridging the discovery and creation views of entrepreneurship. Entrepreneurship Theory and Practice, 34(5), 833-856. doi:10.1111/j.15406520.2010.00395.x

* Eden, D. 1975. Organization membership vs self-employment: Another blow to the american dream. Organizational Behavior and Human Performance, 13, 79-94.

Edwards, J. R. (1992). A cybernetic theory of stress, coping, and well-being in organizations. Academy of Management Review, 17, 238-274.

Edwards, J. R., Caplan, R. D., \& Harrison, R. V. (1998). Person-environment fit theory: Conceptual foundations, empirical evidence, and directions for future research. In C. L. Cooper (Ed.), Theories of organizational stress (pp. 28-67). Oxford: Oxford University Press.

Ellis, A. P. J. (2006). System Breakdown: The role of mental models and transactive memory in the relationship between acute stress and team performance. The Academy of Management Journal, 49(3), 576-589. doi:10.2307/20159782

EU-OSHA. (2014). Calculating the cost of work-related stress and psychosocial risks. European Agency for Safety and Health at Work, Luxembourg. Available at: https://osha.europa.eu/en/publications/literature_reviews/calculating-the-cost-of-workrelated-stress-and-psychosocial-risks. 
Fay, D., \& Sonnentag, S. (2002). Rethinking the effects of stressors: A longitudinal study on personal initiative. Journal of Occupational Health Psychology, 7(3), 221-234.

Fiet, J., Piskounov, A., \& Patel, P. (2005). Still searching (systematically) for entrepreneurial discoveries. Small Business Economics, 25, 489-504.

Freeman, M. A., Johnson, S. L., Staudenmaier, S. J., \& Zisser, M. R. (2015). Are entrepreneurs touched with fire? Technical Report.

Frese, M. (1985). Stress at work and psychosomatic complaints: a causal interpretation. Journal of Applied Psychology, 70(2), 314-328.

Frese, M., Bausch, A., Schmidt, P., Rauch, A., \& Kabst, R. (2012). Evidence-based entrepreneurship (EBE): A systematic approach to cummulative science. In D. Rousseu (Ed.), The Oxford hanbook of evidence based management (pp. 92-111). New York and NY: Oxford University Press.

Frese, M., van Gelderen, M., \& Ombach, M. (2000). How to plan as a small scale business owner: Psychological process characteristics of action strategies and success. Journal of Small Business Management, 38(2), 1-18.

Gaglio, C. M., \& Katz, J. A. (2001). The psychological basis of opportunity identification: Entrepreneurial alertness. Small Business Economics, 16(2), 95-111.

Gardner, D. G. (1990). Task complexity effects on non-task-related movements: A test of activation theory. Organizational behavior and human decision processes, 45(2), 209-231. doi:https://doi.org/10.1016/0749-5978(90)90012-X

Gartner, W. B. (1985). A conceptual framework for describing the phenomenon of new venture creation. Academy of Management Review, 10(4), 696-706.

Gartner, W. B., \& Carter, N. M. (2003). Entrepreneurial behavior and firm organizing processes. In Z. J. Acs \& D. B. Audretsch (Eds.), Handbook of entrepreneurship research (pp. 195-221). Boston and MA: Kluwer. 
Gimeno, J., Folta, T., Cooper, A., \& Woo, C. (1997). Survival of the fittest? Entrepreneurial human capital and the persistence of underperforming firms. Administrative Science Quarterly, 42, 750-783.

* Gorgievski-Duijvesteijn, M. J., Giessen, C. W. M., \& Bakker, A. B. (2000). Financial problems and health complaints among farm couples: Results of a 10-year follow-up study. Journal of Occupational Health Psychology, 5(3), 359-373.

Grégoire, D. A., Barr, P. S., \& Shepherd, D. A. (2010). Cognitive processes of opportunity recognition: The role of structural alignment. Organization Science, 21(2), 413-431. doi:10.1287/orsc. 1090.0462

Gruber, M., MacMillan, I. C., \& Thompson, J. D. (2008). Look before you leap: Market opportunity identification in emerging technology firms. Management Science, 54(9), 1652-1665. doi:10.1287/mnsc.1080.0877

Gunia, B. (2018). The sleep trap: Do sleep problems prompt entrepreneurial motives but undermine entrepreneurial means? Academy of Management Perspectives, in Press. .

Hajkowicz, S. (2015). Global megatrends: Seven patterns of change shaping our future. Brisbane, Qld: CISCO Publishing.

*Harris, J. A., Saltstone, R., \& Fraboni, M. (1999). An evaluation of the Job Stress Questionnaire with a sample of entrepreneurs. Journal of Business and Psychology, 13(3), 447-455

Hatak, I., \& Snellman, K. (2017). The influence of anticipated regret on business start-up behaviour. International Small Business Journal, 35(3), 349-360. doi:10.1177/0266242616673421

Headd, B. (2003). Redefining business success: Distinguishing between closure and failure. Small Business Economics, 21(1), 51-61.

Henrekson, M., \& Johansson, D. (2010). Gazelles as job creators: a survey and interpretation of the evidence. Small Business Economics, 35(2), 227-244. doi:10.1007/s11187-009-9172-z 
Hobfoll, S. E. (1989). Conservation of resources: A new attempt at conceptualizing stress. American Psychologist, 44(3), 513-524.

Humphreys, M. S., \& Revelle, W. (1984). Personality, motivation, and performance - a theory of the relationship between individual-differences and information-processing. Psychological Review, 91(2), 153-184. doi:Doi 10.1037/0033-295x.91.2.153

Jackson, S. E., \& Schuler, R. S. (1985). A meta-analysis and conceptual critique of research on role ambiguity and role conflict in work settings. Organizational Behavior and Human Decision Processes, 36(1), 16-78. doi:10.1016/0749-5978(85)90020-2

* Jamal, M. 1997. Job stress, satisfaction, and mental health: An empirical examination of selfemployed and non-self-employed canadians. Journal of Small Business Management, 35(4), 1857.

* Jamal, M. 2007. Burnout and self-employment: A cross-cultural empirical study. Stress and Health, 23(4), 249-256. doi:10.1002/smi.1144

* Jamal, M., \& Badawi, J. A. 1995. Job stress and quality of working life of self-employed immigrants: A study in workforce diversity. Journal of Small Business \& Entrepreneurship, 12(1), 55-63. doi:10.1080/08276331.1995.10600480

Karasek, R. A. (1990). Lower health risk with increasing job control among white collar workers. Journal of Organizational Behavior, 11(3), 171-185.

Kirzner, I. M. (1997). Entrepreneurial discovery and the competitive market process: An Austrian approach. Journal of Economic Literature, 35(1), 60-85.

Knight, F. H. (1921). Risk, uncertainty, and profit. New York: Kelly and Millman.

Koeske, G. F., \& Koeske, R. D. (1993). A preliminary test of a stress-strain-outcome model for reconceptualizing the burn-out phenomenon. Journal of Social Service Research, 17, 107133.

Lazarus, R. S., \& Folkman, S. (1984). Stress, appraisal and coping. New York: Springer. 
Lepine, J. A., Podsakoff, N. P., \& Lepine, M. A. (2005). A meta-analytic test of the challenge stressor-hindrance stressor framework: An explanation for inconsistent relationships among stressors and performance. The Academy of Management Journal, 48(5), 764-775.

* Lewin-Epstein, N. \& Yuchtman-Yaar, E. 1991. Health risks of self-employment. Work and Occupations, 18, 291-312.

Lupien, S. J., McEwen, B. S., Gunnar, M. R., \& Heim, C. (2009). Effects of stress throughout the lifespan on the brain, behaviour and cognition. Nature Reviews Neuroscience, 10(6), 434-445. doi:10.1038/nrn2639

Luthans, F., Avolio, B. J., Avey, J. B., \& Norman, S. M. (2007). Positive psychological capital: Measurement and relationship with performance and satisfaction. Personnel Psychology, 60(3), 541-572. doi:10.1111/j.1744-6570.2007.00083.x

March, J. G., \& Sutton, R. I. (1997). Crossroads—Organizational performance as a dependent variable. Organization Science, 8(6), 698-706. doi:10.1287/orsc.8.6.698; 15. 10.1287/orsc.8.6.698

Maslach, C. (1982). Burnout: The cost of caring. New York, NY: Prentice-Hall.

Mason, J. W. (1968). A review of psychoendocrine research on the pituitary-adrenal cortical system. Psychosomatic Medicine, 30(5), Suppl:576-607. doi:10.1097/00006842-196809000-00020

McClelland, D. C., \& Winter, D. G. (1971). Motivating economic achievement. New York: Free Press.

McGrath, J. E. (1970). Social and psychological factors of stress. Nwe York: Holt, Rinehart, \& Winston.

McKelvie, A., Haynie, J. M., \& Gustavsson, V. (2011). Unpacking the uncertainty construct: Implications for entrepreneurial action. Journal of Business Venturing, 26(3), 273-292. doi:10.1016/j.jbusvent.2009.10.004 
McMullen, J. S., \& Shepherd, D. A. (2006). Entrepreneurial action and the role of uncertainty in the theory of the entrepreneur. Academy of Management Review, 31(1), 132-152.

Meichenbaum, D. H., \& Deffenbacher, J. L. (1988). Stress inoculation training. The Counseling Psychologist, 16(1), 69-90. doi:10.1177/0011000088161005

Milliken, F. J. (1987). Three types of perceived uncertainty about the environment: State, effect, and response uncertainty. Academy of Management Review, 12(1), 133-143.

Moroz, P. W., \& Hindle, K. (2012). Entrepreneurship as a process: Toward harmonizing multiple perspectives. Entrepreneurship Theory and Practice, 36(4), 781-818. doi:10.1111/j.15406520.2011.00452.x

* Naughton, T. J. 1987. Quality of working life and the self-employed manager. American Journal of Small Business, 12(2), 33-40.

* Parslow, R. A., Jorm, A. F., Christensen, H., Rodgers, B., Strazdins, L., \& D Souza, R. M. 2004. The associations between work stress and mental health: A comparison of organizationally employed and self-employed workers. Work \& Stress, 18(3), 231-244.

Patzelt, H., \& Shepherd, D. A. (2011). Negative emotions of an entrepreneurial career: Selfemployment and regulatory coping behaviors. Journal of Business Venturing, 26(2), 226-238. doi:http://dx.doi.org/10.1016/j.jbusvent.2009.08.002

Peters, A., \& McEwen, B. S. (2015). Stress habituation, body shape and cardiovascular mortality. Neuroscience \& Biobehavioral Reviews, 56, 139-150. doi:https://doi.org/10.1016/j.neubiorev.2015.07.001

Peters, A., McEwen, B. S., \& Friston, K. (2017). Uncertainty and stress: Why it causes diseases and how it is mastered by the brain. Progress in Neurobiology, 156(Supplement C), 164-188. doi:https://doi.org/10.1016/j.pneurobio.2017.05.004 
* Prottas, D. J., \& Thompson, C. A. (2006). Stress, satisfaction, and the work-family interface: A comparison of self-employed business owners, independents, and organizational employees. Journal of Occupational Health Psychology, 11(4), 366-378.

Przepiorka, A. (2016). What makes successful entrepreneurs different in temporal and goalcommitment dimensions? Time \& Society, 25(1), 40-60. doi:10.1177/0961463X15577264; 08

* Rahim, A. 1996. Stress, strain, and their moderators: An empirical comparison of entrepreneurs and managers. Journal of Small Business Management, 34(1), 46-58.

* Rauch, A. 2014. Gruenderstudie 2013/2014 (technical report). Leuphana University Lueneburg, innovation incubator. Unpublished manuscript.

* Rauch A., Unger, J., \& Rosenbusch, N. 2007. The entrepreneur, entrepreneurial stress and long term survival: Is there a causal link? Frontiers of Entrepreneurship Research, Vol 27, No 4. 22 26.

Ropo, A., \& Hunt, J. (1995). Entrepreneurial processes as virtuous and vicious spirals in a changing opportunity structure. Entrepreneurship Theory and Practice, 19(3), 1-111.

Salla, J., Galéra, C., Guichard, E., Tzourio, C., \& Michel, G. (2017). ADHD Symptomatology and perceived stress among French college students. Journal of Attention Disorders, $0(0)$, 1087054716685841. doi:10.1177/1087054716685841

Sandi, C. (2013). Stress and cognition. Wiley Interdisciplinary Reviews: Cognitive Science, 4(3), 245-261. doi:10.1002/wcs. 1222

* Schjoedt, L. (2012). Job design effects on novice and repeat entrepreneurs' job stress. The International Journal of Management and Business, 3(2), 35-52.

Schneider, B., Goldstein, H. W., \& Smith, D. B. (1995). The ASA framework: An update. Personnel Psychology, 48(4), 747-773. doi:10.1111/j.1744-6570.1995.tb01780.x

Schumpeter, J. (1935). Theorie der wirtschaftlichen Entwicklung (Theory of economic growth). Muenchen: Von Duncker und Humbolt. 
Selye, H. (1957). Stress of life. New York: McGraw-Hill Book Company.

Shane, S. (2000). Prior knowledge and the discovery of entrepreneurial opportunities. Organization Science, 11(4), 448-469.

Shane, S. (2003). A general theory of entrepreneurship: The individual-opportunity nexus. Cheltenham and UK: Edward Elgar.

Shane, S., \& Kolvereid, L. (1995). National environment, strategy, and new venture performance: A three country study. Journal of Small Business Management, 33(2), 37.

Shane, S., \& Venkataraman, S. (2000). The promise of entrepreneurship as a field of research. Academy of Management Review, 25(1), 217-226.

Shannon, C. E. (1948). A Mathematical Theory of Communication. Bell System Technical Journal, 27(3), 379-423. doi:10.1002/j.1538-7305.1948.tb01338.x

Sharfman, m. P., \& Dean, J. W. (1991). Conceptualizing and measuring the organizational environment: A multidimensional approach. Journal of Management, 17(4), 681-700.

* Shepherd, C. D., Marchisio, G., Morrish, S. C., Deacon, J. H., \& Miles, M. P. 2010.

Entrepreneurial burnout: Exploring antecedents, dimensions and outcomes. Journal of Research in Marketing and Entrepreneurship, 12(1), 71-79.

Shepherd, D. A., \& Patzelt, H. (2017). Researching the generation, refinement, and exploitation of potential opportunities. In D. A. Shepherd \& H. Patzelt (Eds.), Trailblazing in Entrepreneurship: Creating New Paths for Understanding the Field (pp. 17-62). Cham: Springer International Publishing.

Shepherd, D. A., \& Wolfe, M. T. (2015). Entrepreneurial grief. Wiley Encyclopedia of Management: John Wiley \& Sons, Ltd.

Simmons, S. A., Wiklund, J., \& Levie, J. (2014). Stigma and business failure: implications for entrepreneurs' career choices. Small Business Economics, 42(3), 485-505. doi:10.1007/s11187-013-9519-3 
Stephan, U., \& Roesler, U. (2010). Health of entrepreneurs versus employees in a national representative sample. Journal of Occupational and Organizational Psychology, 83(3), 717738. doi:10.1348/096317909X472067

Stephan, U., \& Uhlander, L. M. (2010). Performance-based vs socially supportive culture: A crossnational study of descriptive norms and entrepreneurship. Journal of International Business Studies, 41, 1347-1364.

Swaminathan, A. (1996). Environmental conditions at founding: A trial-by-fire model. Academy of Management Journal, 39(5), 1350-1377.

Swider, B. W., \& Zimmerman, R. D. (2010). Born to burnout: A meta-analytic path model of personality, job burnout, and work outcomes. Journal of Vocational Behavior, 76(3), 487506. doi:http://dx.doi.org/10.1016/j.jvb.2010.01.003

Tang, J., Kacmar, K. M., \& Busenitz, L. (2012). Entrepreneurial alertness in the pursuit of new opportunities. Journal of Business Venturing, 27(1), 77-94. doi:https://doi.org/10.1016/j.jbusvent.2010.07.001

* Tetrick, L. E., Slack, K. J., Sinclair, R. R., \& DaSilva, N. 2000. A comparison of the stress-strain process for business owners and nonowners: Differences in job demands, emotional exhaustion, satisfaction, and social support. Journal of Occupational Health Psychology, 5(4), 464-476.

Ucbasaran, D., Shepherd, D. A., Lockett, A., \& Lyon, S. J. (2013). Life After Business Failure: The Process and Consequences of Business Failure for Entrepreneurs. Journal of Management, 39(1), 163-202. doi:10.1177/0149206312457823

*Van Eck, J. (2013). Level of stress: A comparison of managers and entrepreneurs (Unpublished thesis). University of Groningen.

Van de Ven, E. H. (1992). Suggestions for studying strategy process: A research note. Strategic Management Journal, 13(S1), 169-188. doi:doi:10.1002/smj.4250131013 
Van Gelderen, M., Kautonen, T., \& Fink, M. (2015). From entrepreneurial intentions to actions: Selfcontrol and action-related doubt, fear, and aversion. Journal of Business Venturing, 30(5), 655-673. doi:https://doi.org/10.1016/j.jbusvent.2015.01.003

Welter, F. (2011). Contextualizing entrepreneurship - conceptual challenges and ways forward. Entrepreneurship Theory and Practice(1), 165-184.

Wiklund, J., Hatak, I., Patzelt, H., \& Shepherd, D. (2018). Mental Disorders in the Entrepreneurial Context: When Being Different Can Be an Advantage. Academy of Management Perspectives, in press.

Wiklund, J., Patzelt, H., \& Dimov, D. (2016). Entrepreneurship and psychological disorders: How ADHD can be productively harnessed. Journal of Business Venturing Insights, 6, 14-20. doi:http://dx.doi.org/10.1016/j.jbvi.2016.07.001

Wincent, J., \& Ortqvist, D. (2009). A comprehensive model of entrepreneur role stress antecedents and consequences. Journal of Business and Psychology, 24(2), 225-243. doi: $10.2307 / 27753902$

* Wincent, J., \& Örtqvist, D. (2011). Examining positive performance implications of role stressors by the indirect influence of positive affect: A study of new business managers. Journal of Applied Social Psychology, 41(3), 699-727. doi:10.1111/j.1559-1816.2011.00733.x

Yerkes, R. M., \& Dodson, J. D. (1908). The relation of strength of stimulus to rapidity of habitformation. Journal of Comparative Neurology and Psychology, 18(5), 459-482. doi:10.1002/cne.920180503

Zwicky, F. (1969). Discovery, invention, research - through the morphological approach. Toronto: The MacMillian Company. 